\title{
Soft tissue artifact compensation in lower extremities using displacement relationship between anatomical landmarks and skin markers
}

Taebeum Ryu*, Moonsoo Shin

From 4th Congress of the International Foot and Ankle Biomechanics (i-FAB) Community

Busan, Korea. 8-11 April 2014

Soft tissue artifact (STA), the deformation of skin and muscle during motion, is known to be one of the important sources of errors in human motion analysis using stereophotogrammetry. As a way to reduce the STA errors, methods estimating positions of anatomical landmarks (AL) have been proposed that keep them rigidly related to the underlying bone. The previous methods [1,2] used intermediate variables such as joint angles or motion time

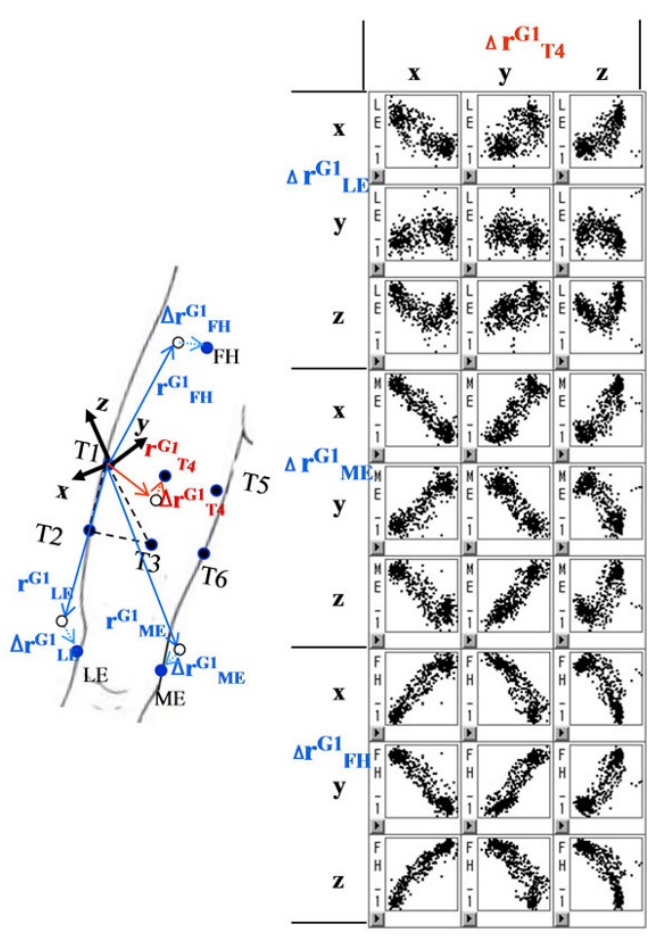

a) Marker group 1

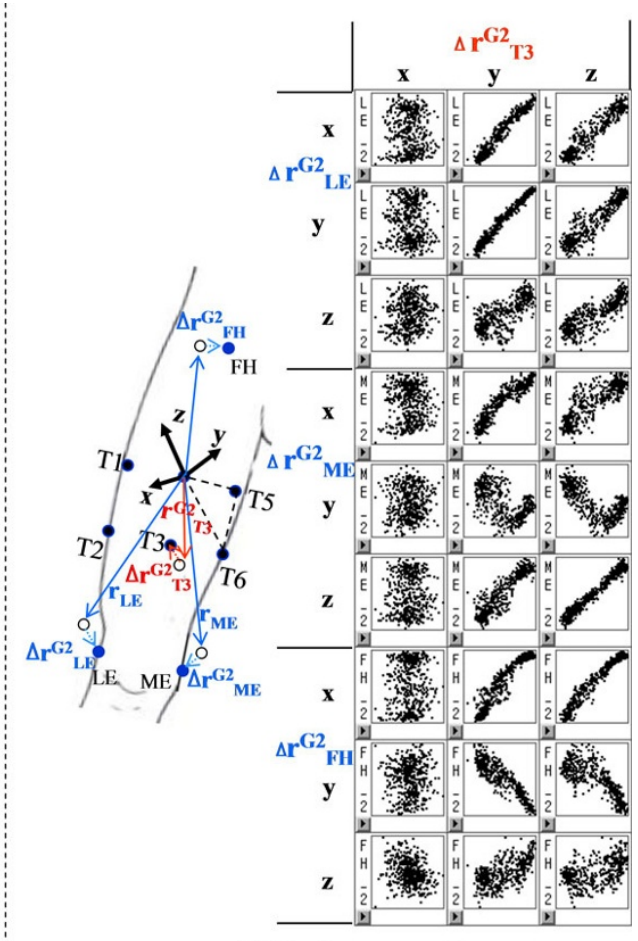

b) Marker group 2

Figure 1 Scatter plot of AL and skin marker displacement in the thigh of a participant

\footnotetext{
* Correspondence: tbryu75@gmail.com

Department of Industrial and Management Engineering, Hanbat National University, Yusung, Daejeon, 305-719, South Korea
} 


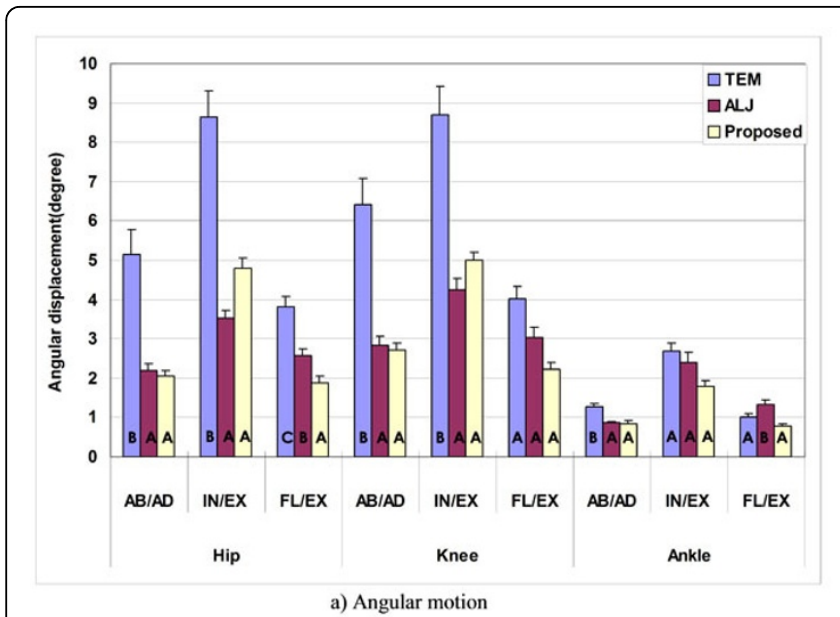

Figure 2 Statistical comparison of compensation methods

to adjust AL positions which were calculated from position data of skin markers. The present study proposes a method to estimate AL positions with skin marker positions directly, thereby removing the intermediate variables of the previous methods. The proposed method identifies a systematic relationship between the displacements of ALs and skin markers relative to a technical coordinate frame defined by skin markers in ad hoc motions(Figure 1). Then, AL positions are calibrated directly by using the displacement relationship with skin markers. The proposed method was applied to analyze three lower extremity motions (walking, sit-to-stand/stand-to-sit and step up/ down) of ten healthy males. Its performance was compared with the transformation error minimization method (TEM) of [3] and the AL estimation method with joint angle (ALJ) of [2]. The proposed method considerably reduced STA errors relative to the TEM (by $30-80 \%$ ) and was also slightly more effective than the ALJ, showing $25-40 \%$ error reductions for seven of 18 kinematic variables(Figure 2).

\section{Trial registration}

Current Controlled Trials ISCRTN73824458.

Published: 8 April 2014

\section{References}

1. Cappello A, Cappozzo A, Palombara PFL, Lucchetti L, Leardini A: Multiple anatomical landmark calibration for optimal bone pose estimation. Human Movement Science 1997, 16:259-274.

2. Lucchetti L, Cappozo A, Cappello A, Croce UD: Skin movement artefact assessment and compensation in the estimation of knee-joint kinematics. Journal of Biomechanics 1998, 31:977-984.

3. Soderkvist I, Wedin P: Determining the movements of the skeleton using well-configured markers. Journal of Biomechanics 1993, 26:1473-1477.

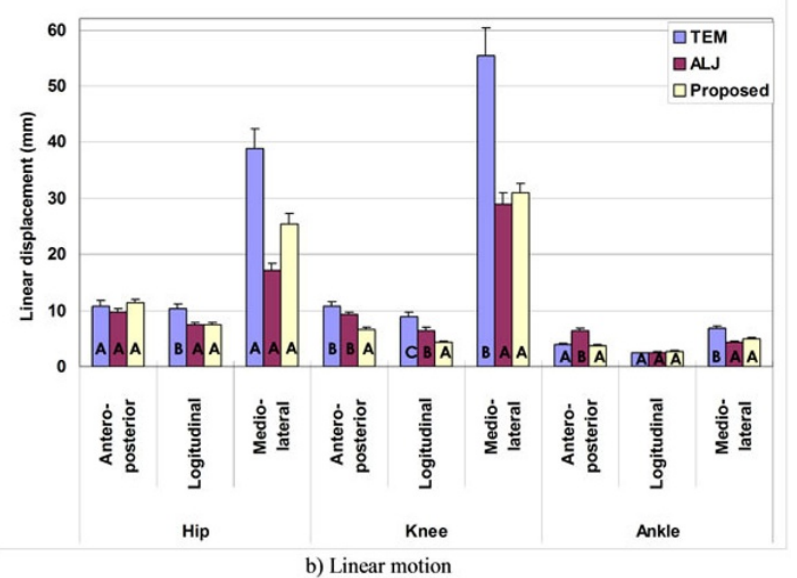

b) Linear motion
doi:10.1186/1757-1146-7-S1-A71

Cite this article as: Ryu and Shin: Soft tissue artifact compensation in lower extremities using displacement relationship between anatomical landmarks and skin markers. Journal of Foot and Ankle Research 2014 7(Suppl 1):A71.
Submit your next manuscript to BioMed Central and take full advantage of:

- Convenient online submission

- Thorough peer review

- No space constraints or color figure charges

- Immediate publication on acceptance

- Inclusion in PubMed, CAS, Scopus and Google Scholar

- Research which is freely available for redistribution

Submit your manuscript at www.biomedcentral.com/submit 